\title{
Locus of semantic interference in picture-word interference tasks
}

\author{
MARKUS F. DAMIAN and JEFFREY S. BOWERS \\ University of Bristol, Bristol, England
}

\begin{abstract}
Picture-word interference studies typically show that semantically related distractor words embedded within a picture slow picture-naming responses, relative to unrelated ones. This semantic interference effect is commonly interpreted as arising from the competition of lexical-semantic (e.g., Schriefers, Meyer, \& Levelt, 1990) or lexical-phonological (e.g., Starreveld \& La Heij, 1996) codes. The experiment reported here tests a crucial assumption shared by these accounts—namely, that the effect reflects a lexical, rather than a nonverbal, conceptual conflict. Pictures were named while participants attempted to ignore embedded distractors that were in either verbal or pictorial format. The presence of both words and pictures substantially interfered with naming responses, but only words, not pictures, were found to induce semantic interference. These findings support the claim that for semantic interference to arise, both target picture and distractor have to be lexicalized. Consequently, a general conceptual locus of the effect can be excluded, and the claim that semantic interference is based on a lexical conflict is confirmed.
\end{abstract}

Speech production requires a speaker to convert a nonlinguistic conceptual message into a linguistic format, a process that involves retrieving words and arranging them in accordance with grammatical rules. The structure of the conceptual system is generally unspecified in models of speech production (although there is currently an active debate concerning whether these representations should be coded in a compositional or a noncompositional format; see, e.g., Caramazza, 1997; Roelofs, 1997). By contrast, detailed models of language processing have been developed that specify the possible mechanisms involved in selecting words on the basis of conceptual input. These include two-step models of speech production that involve retrieving two lexical representations in turn-namely, lexical-semantic (lemma) and lexical-phonological (lexeme) representations (e.g., Levelt, Roelofs, \& Meyer, 1999) — and single-step models that posit only a single lexical level intervening between conceptual and phonological representations (e.g., Caramazza, 1997). Furthermore, processing characteristics may be modular (e.g., Levelt et al., 1999), cascaded (e.g., Humphreys, Riddoch, \& Quinlan, 1988), or interactive (e.g., Dell, 1986).

One of the techniques most commonly used to study word retrieval during production is the picture-word interference (PWI) paradigm: Participants perform timed naming responses to line drawings of basic objects while instructed to ignore (visually or auditorily presented) dis-

Correspondence concerning this article should be addressed to M. F. Damian, University of Bristol, Department of Experimental Psychology, 8 Woodland Road, Bristol BS8 1TN, England (e-mail: m.damian @ bristol.ac.uk). tractor words. The mere presence of a word slows down picture-naming latencies (e.g., W. R. Glaser \& Düngelhoff, 1984). In addition, distractor words semantically related to the picture label have been shown to yield significant interference, as compared with semantically unrelated words (e.g., W. R. Glaser \& Düngelhoff, 1984; Rosinski, Golinkoff, \& Kukish, 1975). In contrast, orthographically or phonologically related distractor words speed up the naming process over unrelated words (e.g., Posnansky \& Rayner, 1977; Rayner \& Springer, 1986). A further variable of interest is the interval between picture and distractor onset (stimulus onset asynchrony, SOA), allowing the assessment of the different processing stages in the picture-naming process. Typically, semantic interference is obtained at negative SOAs (in which distractor onset precedes picture onset, corresponding to an "early" stage of naming preparation), whereas form facilitation effects are found at more positive SOAs (in which distractor onset follows picture onset, corresponding to "late" stage of naming preparation; e.g., Damian \& Martin, 1999; Schriefers, Meyer, \& Levelt, 1990).

Findings from PWI tasks have been used to support various accounts of speech production, including single-step and two-step models. Despite differing interpretations of these results, most of the existing accounts of PWI assume that semantic interference in the PWI paradigm is lexically based and, hence, can be used to illuminate issues of how speaking is orchestrated. This assumption is pervasive in the literature: The present authors have identified approximately 30 papers in the last 25 years that have, explicitly or implicitly, endorsed it. Alternatively, however, semantic interference might merely reflect the coactivation of overlapping representations in preverbal conceptual knowledge (e.g., Lupker \& Katz, 1981; Rayner \& Springer, 
1986): Target and distractor can be assumed to activate closely connected nodes in conceptual memory when they are related and nodes far from each other when they are unrelated. Resolution of the conceptual ambiguity in the related case might take time and, hence, result in interference, relative to the unrelated case. Crucially, if the interference effect were attributable to this processing level, it would not directly speak to issues of lexical access in speech production.

Surprisingly, despite the fact that the lexical basis of semantic interference in PWI is widely accepted, evidence in support of it is scant and inconclusive. Indeed, there are some findings that would appear to suggest that the effect is conceptual, and not lexical. PWI tasks are closely related to studies on the Stroop (1935) effect, and recently it has been argued that both tasks might be accounted for within the same framework (Roelofs, 2003). Within the Stroop domain, there are at least two issues that bear relevance to the question of how semantic interference in PWI should be interpreted. First, in a number of studies, it has been investigated whether the Stroop effect is still obtained if responses are shifted from a naming to a nonverbal task. To the extent that the Stroop effect persists under conditions in which the target need not be lexically encoded, the results would argue against a lexical account of the phenomenon. In a comprehensive review, MacLeod (1991) concluded that Stroop interference cannot entirely be accounted for in terms of a verbal output conflict: Most studies that employed a buttonpress version still obtained interference, albeit substantially reduced (Logan, Zbrodoff, \& Williamson, 1984; Redding \& Gerjets, 1977; Roe, Wilsoncroft, \& Griffiths, 1980; Schmit \& Davis, 1974; Virzi \& Egeth, 1984; but see McClain, 1983). These results suggest that the Stroop effect is obtained even in nonverbal tasks and, hence, caution against prematurely ruling out a conceptual conflict as a contributing factor to semantic interference in PWI.

The second issue investigated in the Stroop domain that is relevant for the present issue is whether interference is obtained when the distractor item is nonverbal-for example, cases in which both the target and the distractor are color patches and the target item is marked by some additional cue. Interference in naming the target color patch would seem to point to a conceptual, rather than a verbal, locus, since the distractors are not presented in verbal format. Several studies have reported interference in such tasks (M. O. Glaser \& W. R. Glaser, 1982; Hagenaar \& van der Heijden, 1986; van der Heijden, 1981; but see La Heij, Helaha, \& van den Hof, 1993, for methodological issues that complicate their interpretation).

Importantly, similar conditions have been tested in picture-naming and PWI tasks. For example, Lupker and Katz (1981, Experiment 1) conducted a PWI experiment that included a manual yes/no decision to pictures ("Is the picture a dog?") that were accompanied by the word "dog," an animal name other than "dog," a non-animalname, a nonword, or no distractor at all. Crucially, semantic interference (e.g., longer response times [RTs] for animal name than for non-animal-name distractors) was obtained despite the fact that the target was not overtly lexicalized, which was thought to indicate that the effect was localized at the decision stage (roughly equivalent to the conceptual, preverbal stage of picture naming), and not at the response selection stage (corresponding to lexical retrieval). Employing the same logic, Schriefers et al. (1990, Experiment 3) reached the opposite conclusion. The authors conducted a control experiment in which picture naming was replaced by a nonverbal semantic task. In a study phase, a set of pictures was shown to participants. In a subsequent test phase, the participants were presented with pictures, some of which had been shown in the study phase, and decided whether they had previously seen the picture by pressing either one of two buttons. Distractor words that were either unrelated or semantically related to the picture were auditorily presented at an SOA of $-150 \mathrm{msec}$. Picture recognition times were shown to be unaffected by the relatedness between targets and distractors. This failure to find semantic interference was interpreted as demonstrating that the effect in PWI is specific to speech production: It occurs only in tasks that require lexical-semantic retrieval of the target stimulus. Yet another pattern of results was obtained by Masson, Bub, and Bukach (2001), who obtained facilitation, instead of the usual interference in a PWI task, when participants were required to perform manual gestures associated with the target objects.

W. R. Glaser and M. O. Glaser (1989, Experiment 6) reported a picture-naming study in which distractors were presented in nonverbal format. Target and distractor pictures were displayed one above the other on the screen, and participants were instructed prior to the start of each SOA block either to name the picture that appeared second and to ignore the picture that appeared first (for blocks with negative SOAs) or vice versa (for positive SOAs). SOAs ranged from -300 to $+300 \mathrm{msec}$. A significant difference between the unrelated and the related conditions was found at SOAs between -75 and $+100 \mathrm{msec}$. Under the assumption that distractor pictures were not recoded into a verbal format, this finding argues for a conceptual basis for the interference effect.

In summary, the current evidence is mixed with regard to the locus of the PWI, and furthermore, each of the picture-naming and PWI findings described above can be challenged. Lupker and Katz's (1981) finding of semantic interference in a manual task might in fact have a verbal basis: In this experiment, all target objects were compared with a single semantic reference category ("Is it a dog?"), and under these circumstances, participants may have verbalized each target and responded on the basis of the verbal label (responding "yes" if the label "dog" was generated and "no" otherwise). Indeed, in order to avoid a similar confound of implicit verbal coding, Schriefers et al. (1990) analyzed only "no" responses in their picture recognition task, and as was noted above, they failed to find a semantic effect. Unfortunately, in order to argue for a lexical basis for the PWI effect, these authors had 
to assume that performance on their picture recognition task required full access to semantic representations. Yet, it is quite possible that the participants largely or exclusively based their decisions on perceptual representations, responding positively when the same perceptual codes were contacted at study and test and negatively otherwise. Consistent with this possibility, prior research has demonstrated an impressive capacity of visual memory in humans (Shepard, 1967; Standing, 1973). Consequently, the participants might have performed the picture recognition task without consulting semantic information, and this would undermine the validity of the task with regard to the origin of the semantic interference effect in picture naming.

With regards to W. R. Glaser and M. O. Glaser's (1989) picture-picture interference procedure, some experiments on our part revealed that for those SOAs in which interference was reported, the interval between target and distractor onset was so short that it would be difficult to disambiguate the two items. Consequently, owing to situational demands, the participants might have verbally encoded both pictures and subsequently decided which one was the target to name. ${ }^{1}$ Furthermore, in W. R. Glaser and M. O. Glaser's study, the same pictures served as the targets and the distractors (i.e., distractors were members of the response set). If a picture has been repeatedly processed as the target to the verbal level, it is not unlikely that it will evoke its label when presented as a distractor, in which case the findings would not constitute an adequate test of the locus of semantic interference. Finally, semantically related objects usually have a higher degree of visual overlap than do unrelated ones (e.g., Snodgrass \& McCullough, 1986). Hence, W. R. Glaser and M. O. Glaser's interference effect might have resulted from higher visual confusability in the related condition than in the unrelated condition, rather than from semantic overlap.

Also, at least one failure to obtain picture-picture interference has been reported: Humphreys, Lloyd-Jones, and Fias (1995) introduced a so-called postcue procedure in which two partially overlapping pictures were presented and participants were, after a particular time interval (e.g., 500 or $2,000 \mathrm{msec}$ ), cued as to which picture to name. Distractor pictures that were categorically related to the target pictures consistently slowed responses, relative to unrelated distractors. Crucially, however, this was only the case if the cue was provided at some interval after stimulus presentation. On the other hand, if targets were unambiguously identifiable from presentation onset by means of color instead of a postcue (Experiment 2), no interference was obtained. Possibly, the participants verbalized both pictures in the postcue condition, but only the target in the color cue condition, inducing a (lexically based) conflict only in the former case, but not in the latter. This assumption does not conflict with the finding that, when words were used as targets (Experiment 4A), again no interference was found: Word processing probably does not emphasize conceptual characteristics to the same degree as picture processing. Also note that, using a similar technique, Dean, Bub, and Masson (2001) obtained interference when target pictures had to be manually categorized according to color. This finding might indicate that the participants covertly recoded picture stimuli into a verbal format as they prepared for the cued response.

The present investigation provides another attempt to identify the locus of semantic interference in PWI by addressing the above concerns. We adopt W. R. Glaser and M. O. Glaser's (1989) general approach of using pictorial distractors but improve on their procedure in the following ways. First, to facilitate discrimination between the target and the distractor, the distractor picture is embedded within the target, as is normally the case for visual word distractors in PWI tasks (see Figure 1). The procedure is, therefore, similar to conventionalPWI tasks, in that both stimuli overlap and are, therefore, spatially integrated, except that pictures, instead of words, constitute the distractors. Second, different sets of pictures serve as targets and distractors, eliminating the possibility that verbal encoding of pictures in their role as targets induces involuntary verbal encoding when they are used as distractors. Finally, stimuli are selected so that targets and distractors in the related and the unrelated conditions share an equal degree of visual overlap. Also, like W. R. Glaser and M. O. Glaser's experiment, we included an entire range of SOAs $(-200,-100,0$, and $+100 \mathrm{msec})$, reducing the possibility that a potential null finding for
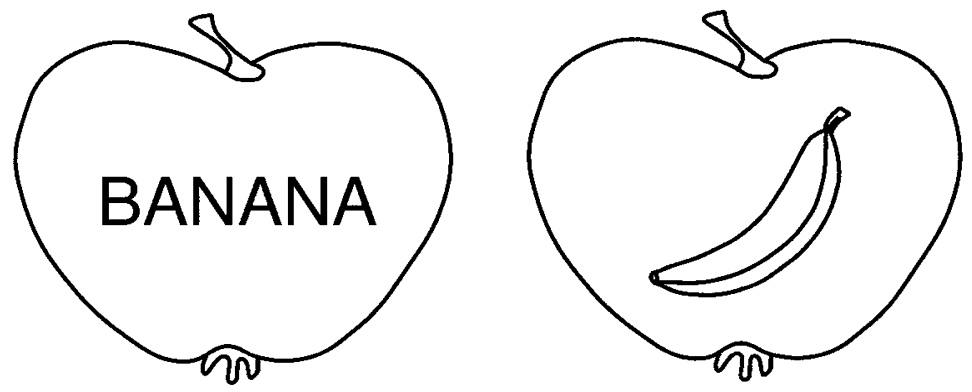

Figure 1. Example of picture-word (left) and picture-picture (right) interference displays. 
pictorial distractors-as predicted by the lexical interference hypothesis-went undetected by "missing" the crucial stage of naming.

The hypothesis that semantic interference is based on conceptual overlap, rather than on a lexical retrieval conflict, clearly predicts that the input format of the distractor should not bear any relevance and, consequently, pictures should be as effective semantic distractors as words are. Indeed, some findings suggest that pictures are at least as fast (if not faster) in accessing conceptual representations, as compared with words (Bowers, Vigliocco, StadthagenGonzales, \& Vinson, 1999; Potter \& Faulconer, 1975), and that, accordingly, distractor pictures might be expected to produce larger interference if conceptual representations support the effect. In contrast, the hypothesis that semantic interference is based on a lexical retrieval conflict would predict no picture-picture interference.

\section{METHOD}

\section{Participants}

Twenty-eight undergraduate students from the participants pool of the Max Planck Institute for Psycholinguistics took part in this experiment in exchange for pay. All were native speakers of Dutch and had normal or corrected-to-normal vision.

\section{Materials}

Eighteen black-and-white line drawings of common objects from the Snodgrass and Vanderwart (1980) set of pictures were selected as the targets from various semantic categories, with the restriction that superimposing a distractor stimulus would not impair their recognizability. To form semantically related target-distractor pairs, each picture was paired with a further picture from the same semantic category. Care was taken to choose pairs in which both pictures were maximally visually dissimilar. To choose semantically unrelated target-distractor pairs whose visual similarity was closely matched to that of the related pairs, the following procedure was adopted. The semantically related picture pairs, as well as a large number of semantically unrelated picture pairs that were randomly generated from the same set, were rated according to their visual similarity in a preexperiment. Twenty participants, none of whom participated in the main experiment, were presented with two pictures side by side and were instructed to ignore the semantic content of the pictures and to exclusively rate the surface similarity on a scale ranging from 1 (not at all similar) to 5 (very similar). From the results, each target picture was paired with a semantically unrelated picture whose visual overlap score was as close as possible to the one obtained from the semantically related one. The resulting set of picture pairings indicated a visual similarity rating of 2.56 $(S D=0.68)$ for semantically related picture pairs and a rating of $2.32(S D=0.69)$ for the unrelated pairs. The difference of $0.24 \mathrm{did}$ not significantly deviate from zero $[t(17)=1.19, p=.250]$. Hence, related and unrelated target-distractor pairs were matched closely with regard to their respective visual overlap. None of the resulting pairings were phonologically related (see the Appendix for a listing of the stimuli). A further condition was included in which no distractor was presented (control condition).

\section{Design}

The experimental design included distractor type (word vs. picture), SOA $(-200,-100,0$, and $+100 \mathrm{msec}$ ), and relatedness (unrelated vs. related vs. control) as within-subjects factors. The order in which the participants received the SOA blocks was balanced according to a Latin-square design.

\section{Apparatus}

The stimuli were presented as black line drawings on white background from an IBM-compatible computer on a NEC MultiSync 3D computer screen using NESU (Nijmegen Experimental Set Up). Responses were measured to the nearest millisecond with a microphone (Sennheiser ME40) connected to a voice-activated relay. Target pictures were enlarged to a size of approximately $18 \times 18 \mathrm{~cm}$, and distractor pictures were shrunk to a size of approximately $8 \times$ $8 \mathrm{~cm}$. Distractor words were presented in black uppercase Helvetica 36 Bold font in the center of each target picture.

\section{Procedure}

The participants were tested individually. At the beginning of the experiment, they were familiarized with the set of experimental pictures by viewing each picture on the computer screen for 2,000 msec with the appropriate name printed below it. Following this familiarization phase, a practice block was administered in which the participants performed a naming response to each of the pictures, presented in random order. Next, a practice block was administered that presented the pictures accompanied by unrelated distractor words. Finally, four experimental blocks, corresponding to the four SOAs, were carried out, consisting of 90 critical naming responses each, preceded by two filler trials. Breaks were provided between the experimental blocks. Items were presented in a pseudorandomized order, with the constraint that the same picture was never shown on subsequent trials. Each testing session consisted of 368 experimental trials and lasted approximately $30 \mathrm{~min}$.

On each individual trial, the participants first viewed a fixation cross presented at the center of the screen for 1,000 msec. After a blank interval of $500 \mathrm{msec}$, the target picture appeared. At varying intervals before or after the picture onset (depending on the SOA block), the distractor word or picture was presented at the center of the picture; within each block, each picture was also presented and named once without a distractor (control condition). The participants performed the naming response on the large target picture by speaking the picture label into a microphone. The picture and the distractor stimulus disappeared from the screen as soon as the voice key was triggered. Following each naming response, the experimenter judged the response to be either correct or incorrect; incorrect responses included wrong or incomplete responses, mouth clicks, and equipment malfunctioning. Each trial was concluded by a 1,500-msec intertrial interval.

\section{Results}

Responses judged to be incorrect by the experimenter for the reasons described above, latencies larger than $1,500 \mathrm{msec}$ or smaller than $250 \mathrm{msec}$ and latencies deviating more than three $S D$ s from a participant's conditional meaning were eliminated $(4.1 \%)$. Table 1 displays the mean RTs, varied by SOA, type of distractor, and relatedness; the mean for the control condition reflects the average latency for targets presented without distractors within the corresponding SOA block.

Effects of relatedness (the difference between the related and the unrelated condition) on latencies were assessed by planned $t$ tests for each distractor type (pictures vs. words) and SOA level. For word distractors, these tests revealed a significant interference at $\mathrm{SOA}=0 \mathrm{msec}$ $\left[t_{1}(27)=3.05, p=.005 ; t_{2}(17)=2.92, p=.010\right]$, but not at any of the other SOAs $(t \mathrm{~s} \leq 1.10)$. For picture distractors, none of the comparisons was statistically significant $(t \mathrm{~s} \leq 1.28)$. It therefore appears that semantic interference effects are restricted to word distractors at an SOA of $0 \mathrm{msec}$. And indeed, an additional test that compared 
Table 1

Mean Response Latencies (RT, in Milliseconds) and Error Proportions (PE, in \%), Varied by Relatedness (Unrelated vs. Related vs. Control), Distractor Type (Word vs. Picture), and Picture-Word Stimulus Onset Asynchrony (SOA)

\begin{tabular}{|c|c|c|c|c|c|c|c|c|c|c|c|c|c|c|c|c|}
\hline \multirow{3}{*}{ Condition } & \multicolumn{16}{|c|}{ SOA (msec) } \\
\hline & \multicolumn{4}{|c|}{-200} & \multicolumn{4}{|c|}{-100} & \multicolumn{4}{|c|}{0} & \multicolumn{4}{|c|}{+100} \\
\hline & \multicolumn{2}{|c|}{ RT } & \multicolumn{2}{|c|}{$\mathrm{PE}$} & \multicolumn{2}{|c|}{ RT } & \multicolumn{2}{|c|}{$\mathrm{PE}$} & \multicolumn{2}{|c|}{ RT } & \multicolumn{2}{|c|}{$\mathrm{PE}$} & \multicolumn{2}{|c|}{ RT } & \multicolumn{2}{|c|}{$\mathrm{PE}$} \\
\hline \multicolumn{17}{|c|}{ Word distractors } \\
\hline Unrelated & 612 & 70 & 2.6 & 5.6 & 616 & 70 & 1.8 & 3.4 & 641 & 78 & 1.2 & 2.8 & 667 & 85 & 3.0 & 3.9 \\
\hline Related & 615 & 68 & 3.2 & 4.1 & 621 & 76 & 1.6 & 3.0 & 657 & 83 & 4.2 & 4.9 & 669 & 90 & 5.0 & 6.1 \\
\hline Unrelated & 619 & 66 & 1.8 & 4.0 & 607 & 61 & 1.8 & 3.3 & 589 & 74 & 1.2 & 2.8 & 584 & 72 & 3.8 & 5.5 \\
\hline Related & 621 & 65 & 2.4 & 4.1 & 603 & 62 & 2.4 & 3.8 & 586 & 79 & 2.0 & 4.6 & 586 & 72 & 3.2 & 6.7 \\
\hline Effect & -2 & & -0.6 & & 4 & & -0.6 & & 3 & & -0.8 & & -2 & & 0.6 & \\
\hline Control & 602 & 77 & 2.6 & 5.6 & 578 & 61 & 2.0 & 3.1 & 575 & 62 & 2.4 & 4.1 & 570 & 65 & 2.2 & 5.1 \\
\hline
\end{tabular}

$* p<.05 . \quad * * p<.01$.

the size of the relatedness effect for word distractors to the one for picture distractors at that SOA was significant $\left[t_{1}(27)=2.84, p=.008 ; t_{2}(17)=2.85, p=.011\right]$.

If picture distractors were equivalent to word distractors, one should expect a significant difference to appear for the pictures at the same SOA- $0 \mathrm{msec}$. A power analysis performed on the test for picture distractors showed a value of 0.84 to detect an effect equal in size to the one obtained with word distractors under this SOA. It is thus unlikely that lack of statistical power caused the failure to obtain a significant difference with picture distractors.

A further comparison of interest is between the control condition and the various unrelated conditions under each SOA in order to assess the degree of interference caused by the mere presence of a distractor word or a picture. For word distractors, all comparisons were highly significant ( $t \mathrm{~s} \geq 5.12)$, except for SOA $=-200 \mathrm{msec}$, at which the comparison was not significant by subjects $\left(t_{1}=1.26\right)$ and was marginally significant by items $\left[t_{2}(27)=1.89, p=\right.$ .076]. Likewise, for picture distractors, all comparisons were significant $(t \mathrm{~s} \geq 2.39$ ), except for SOA $=-200 \mathrm{msec}$, at which the comparison was marginally significant by subjects $\left[t_{1}(17)=1.98, p=.058\right]$ and was significant by items $\left[t_{2}(27)=2.70, p=.015\right]$. Hence, the mere presence of a distractor - verbal or pictorial—significantly slowed down responses, with the exception of SOA $=-200 \mathrm{msec}$, at which distractors apparently were presented too early to have an effect on the naming process.

Analyses conducted on the errors, which compared the related with the unrelated condition under each distractor type and SOA level, revealed a significant difference only for word distractors at SOA $=0 \mathrm{msec}\left[t_{1}(27)=\right.$ $\left.3.22, p=.003 ; t_{2}(18)=2.48, p=.024\right]$. All other comparisons for word distractors did not reach significance $(t \mathrm{~s} \leq 1.54)$, and neither did any of the comparisons for picture distractors $(t \mathrm{~s} \leq 1.29)$. Hence, the pattern closely paralleled the one obtained for latencies.

\section{DISCUSSION}

In accordance with a number of existing studies on PWI (e.g., Damian \& Martin, 1999; W. R. Glaser \& Düngelhoff,
1984; Starreveld \& La Heij, 1996), semantically related word distractors induced an interference effect, relative to unrelated ones, predominantly at an SOA of $0 \mathrm{msec}$. Critically, however, a semantic relation between pictorial distractors and targets did not influence RTs. This shows that distractors have to be encoded in a verbal format to produce semantic interference and that, hence, the semantic interference effect obtained with word distractors is most likely lexical. This supports the widespread use of the PWI paradigm as a tool for addressing questions about word retrieval in speech production. Of course, this observation does not directly address which levels of lexical retrieval are involved. For instance, in the account of PWI introduced by Roelofs (1992), lexical-semantic entries compete for selection, whereas in Starreveld and La Heij's model of PWI, phonological codes are in competition. The present findings could be accommodated in either framework. But crucially, they support the common critical assumption that the locus of the underlying conflict is lexical and not merely conceptual.

Interestingly, the assumption that picture distractors gain access to conceptual, but not to lexical, codes is not easily implemented in existing models of speech production, which usually propose that activation spreads automatically from the conceptual level to the lexical. In contrast, the present findings suggest that lexical codes are accessed only if this is necessary for the task (as in the naming of picture targets) or if the distractor is already in verbal format (as for word distractors). What would seem to be required is some kind of a blocking mechanism between the conceptual and the lexical levels that selectively permits or denies transmission of activation between the two levels according to circumstantial factors, such as usefulness (see Bloem \& La Heij, 2000 , for a similar conclusion and some computational suggestions).

It is worth discussing possible alternative reasons for our failure to obtain a semantic effect from pictorial distractors. It has been argued (e.g., W. R. Glaser \& M. O. Glaser, 1989, p. 29) that distractors will not interfere with target processing if participants are able to "narrow" their visual selection and, hence, eliminate distractor pro- 
cessing at an early stage (as, e.g., in Stroop tasks in which the target and the distractor are not spatially integrated and the target is always presented in the same location). Could it be the case that participants were somehow more effective in visually "tuning out" pictorial distractors than they were with verbal distractors, despite the fact that distractors were always spatially integrated with the target? To test this possibility, we conducted a control experiment in which the targets were manually categorized as either man-made or natural. The targets from the experiment reported above consisted of 11 man-made and 7 natural objects; to balance the categories, four additional natural targets were added. Pictorial distractorsthe distractors from Experiment 1, plus four additional natural distractors-were paired with the targets so that both were either from the same category (congruent) or from different categories (incongruent). If indeed distractor pictures are conceptually processed while making a decision on the target, a congruity effect should be expected. To minimize the chance that the participants strategically employed information derived from the distractor on congruent trials, further incongruent pairs were inserted as fillers so that the overall percentage of congruent trials was $25 \%$. Targets and distractors were presented simultaneously ( $\mathrm{SOA}=0 \mathrm{msec}$ ), the condition in which interference was obtained with word distractors. The results from 12 participants showed a substantial congruity effect (related mean, $564 \mathrm{msec}$; unrelated mean, $596 \mathrm{msec}$; identical error rates of $4.6 \%$ ) that was significant by subjects and by items $(p s<.05)$. Hence, the distractor pictures were clearly processed at a conceptual level and provided enough input to evoke a substantial congruity effect.

The study leaves open the question of why, as was discussed in the introduction, some studies conducted in the Stroop domain appear to show semantic interference in nonverbal tasks: if, as we have argued, the locus of the semantic effect in PWI is lexical and a common mechanism underlies the effect in Stroop and PWI tasks, these results would appear to be left unaccounted for. Of course, it is possible that Stroop and PWI experiments, although closely related, might differ in important aspects. For instance, in Stroop experiments, semantic relatedness is oftentimes confounded with semantic relevance (La Heij, 1988): These tasks employ only a single semantic category (e.g., color), and an incongruent color distractor, therefore, not only is semantically related to the target, but also is highly relevant in a color-naming task, in that it provides a plausible response. This should be less important in PWI experiments, in which several semantic categories can be used and in which semantic relatedness should contribute more to semantic interference than does task relevance. Accordingly, it cannot be taken for granted that results in one domain will entirely parallel those in the other. A further unexplained finding remains Lupker and Katz's (1981) finding of interference in a manual version of PWI (but see the introduction for a possible explanation of this finding on the basis of implicit verbal coding). ${ }^{2}$
Regardless of these unresolved issues, however, the present findings clearly demonstrate that semantic interference is eliminated in a picture-naming task in which distractor items are not verbally encoded. Accordingly, the claim that semantically related distractors interfere with picture-naming responses at a lexical rather than a conceptual level receives support; clearly, this effect appears to reflect processes specific to speech production.

\section{REFERENCES}

Bloem, I., \& La HeIJ, W. (2000, November). Semantic facilitation and semantic interference in word translation: Implications for models of lexical access. Paper presented at the 41st Annual Meeting of the Psychonomic Society, New Orleans.

Bowers, J. S., Vigliocco, G., Stadthagen-Gonzales, H., \& Vinson, D. (1999). Distinguishing language from thought: Experimental evidence that syntax is lexically rather than conceptually represented. Psychological Science, 10, 310-315.

Caramazza, A. (1997). How many levels of processing are there in lexical access? Cognitive Neuropsychology, 14, 177-208.

Damian, M., \& Martin, R. C. (1999). Semantic and phonological codes interact in single word production. Journal of Experimental Psychology: Learning, Memory, \& Cognition, 25, 345-361.

Dean, M. P., Bub, D. N., \& Masson, M. E. J. (2001). Interference from related items in object identification. Journal of Experimental Psychology: Learning, Memory, \& Cognition, 27, 733-743.

DeLl, G. S. (1986). A spreading activation theory of retrieval in sentence production. Psychological Review, 93, 283-321.

Glaser, M. O., \& Glaser, W. R. (1982). Time course analysis of the Stroop phenomenon. Journal of Experimental Psychology: Human Perception \& Performance, 8, 875-894.

Glaser, W. R, \& Düngelhoff, F.-J. (1984). The time course of pictureword interference. Journal of Experimental Psychology: Human Perception \& Performance, 10, 640-654.

Glaser, W. R. \& Glaser, M. O. (1989). Context effects in Stroop-like word and picture processing. Journal of Experimental Psychology: General, 118, 13-42.

HagenaAr, R, \& van der Heijden, A. H. C. (1986). Target-noise separation in visual selective attention. Acta Psychologica, 62, 161-176.

Humphreys, G. W., Lloy D-Jones, T. J., \& Fias, W. (1995). Semantic interference effects on naming using a postcue procedure: Tapping the links between semantics and phonology with pictures and words. Journal of Experimental Psychology: Learning, Memory, \& Cognition, 21, 961-980.

Humphreys, G. W., Riddoch, M. J., \& Quinlan, P. T. (1988). Cascade processes in picture identification. Cognitive Neuropsychology, 5, 67-103.

LA HeIJ, W. (1988). Components of Stroop-like interference in picture naming. Memory \& Cognition, 16, 400-410.

La Heis, W., Helaha, D., \& van den Hof, E. (1993). Why does blue hamper the naming of red? Color-color interference and the role of locational (un)certainty. Acta Psychologica, 83, 159-177.

Levelt, W. J. M., Roelofs, A., \& Meyer, A. S. (1999). A theory of lexical access in speech production. Behavioral \& Brain Sciences, 22, 1-75.

Logan, G. D., Zbrodoff, N. J., \& Williamson, J. (1984). Strategies in the color-word Stroop task. Bulletin of the Psychonomic Society, 22, 135-138.

LUPKER, S. J., \& KATZ, A. N. (1981). Input, decision, and response factors in picture-word interference. Journal of Experimental Psychology: Human Learning \& Memory, 7, 269-282.

MacLeod, C. M. (1991). Half a century of research on the Stroop effect: An integrative review. Psychological Bulletin, 109, 163-203.

Masson, M. E. J., Bub, D. N., \& Bukach, C. M. (2001, April). Differential contributions of functional and associative knowledge to object and word identification. Paper presented at the Annual Australian Experimental Psychology Conference, Melbourne.

McClain, L. (1983). Effects of response type and set size on Stroop color-word performance. Perceptual \& Motor Skills, 56, 735-743.

Posnansky, C. J., \& RAYner, K. (1977). Visual-feature and response 
components in a picture-word interference task with beginning and skilled readers. Journal of Experimental Child Psychology, 24, 440449.

Potter, M. C., \& Faulconer, B. A. (1975). Time to understand pictures and words. Nature, 253, 437-438.

RAyner, K., \& Springer, C. J. (1986). Graphemic and semantic similarity effects in the picture-word interference task. British Journal of Psychology, 77, 207-222.

Redding, G. M., \& GerJets, D. A. (1977). Stroop effect: Interference and facilitation with verbal and manual responses. Perceptual \& Motor Skills, 45, 11-17.

Roe, W. T., Wilsoncroft, W. E., \& Griffiths, R. S. (1980). Effects of motor and verbal practice in the Stroop task. Perceptual \& Motor Skills, 50, 647-650.

Roelofs, A. (1992). A spreading-activation theory of lemma retrieval in speaking. Cognition, 42, 107-142.

RoElofs, A. (1997). A case for nondecomposition in conceptually driven word retrieval. Journal of Psycholinguistic Research, 26, 33-67.

Roelofs, A. (2003). Goal-referenced selection of verbal actions: Modeling attentional control in the Stroop task. Psychological Review, 110, 88-125.

Rosinski, R. R., Golinkoff, R. M., \& Kukish, K. S. (1975). Automatic semantic processing in a picture-word interference task. Child Development, 46, 247-253.

Schmit, V., \& Davis, R. (1974). The role of hemispheric specialization in the analysis of Stroop stimuli. Acta Psychologica, 38, 149-158.

Schriefers, H., Meyer, A. S., \& Levelt, W. J. M. (1990). Exploring the time course of lexical access in language production: Pictureword interference studies. Journal of Memory \& Language, 29, 86102.

SHEPARD, R. N. (1967). Recognition memory for words, sentences, and pictures. Journal of Verbal Learning \& Verbal Behavior, 6, 156-163.

Snodgrass, J. G., \& McCullough, B. (1986). The role of visual similarity in picture categorization. Journal of Experimental Psychology: Learning, Memory, \& Cognition, 12, 147-154.
Snodgrass, J. G., \& Vanderwart, M. (1980). A standardized set of 260 pictures: Norms for name agreement, image agreement, familiarity, and visual complexity. Journal of Experimental Psychology: Human Learning \& Memory, 6, 174-215.

STANDING, L. (1973). Learning 10,000 pictures. Quarterly Journal of Experimental Psychology, 25, 207-222.

Starreveld, P. A., \& La Heis, W. (1996). Time-course analysis of semantic and orthog raphic context effects in picture naming. Journal of Experimental Psychology: Learning, Memory, \& Cognition, 22, 869918.

Stroop, J. R. (1935). Studies of interference in serial verbal reactions. Journal of Experimental Psychology, 18, 643-662.

VAN DER HEIJDEN, A. H. C. (1981). Short-term visual information forgetting. London: Routledge \& Kegan Paul.

Virzi, R. A., \& Egeth, H. E. (1984). Is meaning implicated in illusory conjunctions? Journal of Experimental Psychology: Human Perception \& Performance, 10, 573-580.

\section{NOTES}

1. Note that La Heij et al. (1993) put forward a similar argument to criticize color-color Stroop tasks that present targets under conditions of locational uncertainty - that is, conditions in which the positions of the target and the distractor vary from trial to trial. La Heij et al. obtained interference under these circumstances; however, when target position was fixed, color distractors did not interfere with color naming. These results were, in fact, taken to argue for a verbal (and against a conceptual) locus of the interference effect.

2. Damian, Bowers, and Katz (unpublished data) conducted an experiment in which a manual animacy judgment was performed on pictures and distractors were auditorily presented at various SOAs. In accordance with Schriefers et al. (1990), but contra Lupker and Katz (1981), we failed to obtain semantic interference at any of the investigated SOAs, which further underscores the fact that the effect is specific to verbal response tasks.

\section{APPENDIX}

Stimuli Used in the Experiment

\begin{tabular}{lll}
\hline \multicolumn{1}{c}{ Target } & \multicolumn{1}{c}{$\begin{array}{c}\text { Related } \\
\text { Distractor }\end{array}$} & \multicolumn{1}{c}{$\begin{array}{c}\text { Unrelated } \\
\text { Distractor }\end{array}$} \\
\hline Appel (apple) & Banaan (banana) & Hemd (shirt) \\
Bank (sofa) & Kruk (stool) & Schaar (scissors) \\
Bed (bed) & Stoel (chair) & Jurk (dress) \\
Brood (bread) & Taart (cake) & Gitaar (guitar) \\
Voet (foot) & Oor (ear) & Varken (pig) \\
Geit (goat) & Varken (pig) & Tas (cup) \\
Glas (glass) & Tas (cup) & Vest (vest) \\
Hand (hand) & Oog (eye) & Vis (fish) \\
Kan (pitcher) & Fles (bottle) & Stoel (chair) \\
Kikker (frog) & Vis (fish) & Banaan (banana) \\
Peer (pear) & Ananas (pineapple) & Fles (bottle) \\
Pet (cap) & Jurk (dress) & Vaas (vase) \\
Rok (skirt) & Vest (vest) & Ananas (pineapple) \\
Schaal (bowl) & Vaas (vase) & Taart (cake) \\
Sok (sock) & Hemd (shirt) & Wortel (carrot) \\
Trommel (drum) & Gitaar (guitar) & Kruk (stool) \\
Ui (onion) & Wortel (carrot) & Oor (ear) \\
Zaag (saw) & Schaar (scissors) & Oog (eye) \\
\hline
\end{tabular}

Note-The appropriate English translation is given in parentheses. 